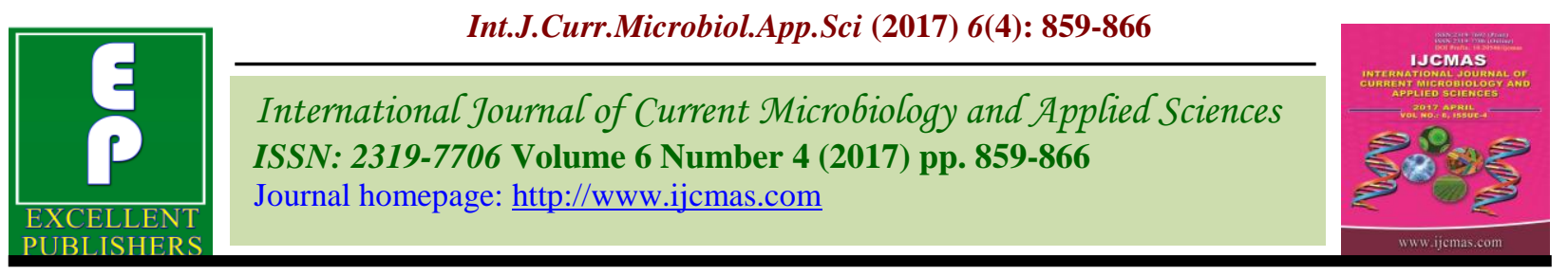

Review Article

https://doi.org/10.20546/ijcmas.2017.604.107

\title{
Role of Biochar in Mitigation of Climate Change through Carbon Sequestration
}

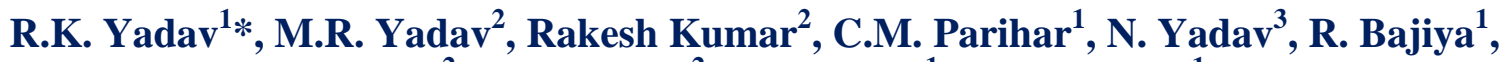 \\ H. Ram ${ }^{2}$, R.K. Meena ${ }^{2}$, D.K.Yadav ${ }^{1}$ and B. Yadav ${ }^{1}$ \\ ${ }^{1}$ ICAR- Indian Agricultural Research Institute, New Delhi-110 012, India \\ ${ }^{2}$ ICAR- National Dairy Research Institute, Karnal-132001, India \\ ${ }^{3}$ Institute of Agricultural Sciences, BHU, Varanasi-221005, India \\ *Corresponding author
}

\begin{tabular}{|c|c|}
\hline & B S T R A C T \\
\hline & \multirow{6}{*}{$\begin{array}{l}\text { Biochar is a carbon rich charcoal-like substance created by thermal decomposition biomass } \\
\text { (organic matter) in low oxygen conditions at relatively low temperatures }\left(<700^{\circ} \mathrm{C}\right) \text {, a } \\
\text { process known as pyrolysis. Biochar is essentially fine-grained charcoal made up of stable } \\
\text { organic material and applied to soils in order to achieve net carbon sequestration, which is } \\
\text { being promoted primarily for counterbalancing the impact of climate change and for } \\
\text { sustaining soil fertility status. Currently, there is a clear cut evidence of large imbalance } \\
\text { between carbon emission to the atmosphere and carbon uptake by the plants for the } \\
\text { process of photosynthesis which leads to a continued increase in atmospheric } \mathrm{CO}_{2} \text { over } \\
\text { long run. Formation of biochar formed though pyrolysis of plant biomass and its } \\
\text { application to the in order to achieve higher storage of carbon in soils has been suggested } \\
\text { as a means to counterbalance the effect of climate change by sequestering carbon. The } \\
\text { principal mechanisms operating in soils through which biochar entering the soil is } \\
\text { stabilized and significantly increase its life cycle in soil are its particulate nature, } \\
\text { recalcitrance, mean residence time and interaction with mineral surfaces. To derive the } \\
\text { maximum possible benefit of carbon sequestration through application of biochar, both } \\
\text { yield and stability of the biochar are two important factors and should be optimized. The } \\
\text { benefits of carbon sequestration through biochar are more visible in soils lower in carbon } \\
\text { than soils relatively higher in carbon. Research evidence suggests that adoption of biochar } \\
\text { technology in proper way can address the emerging challenges of agricultural sector and } \\
\text { conserve/improve the quality of environment. In this review we evaluate the potential of } \\
\text { biochar to reimbursement the current issues related to carbon sequestration. }\end{array}$} \\
\hline Keywords & \\
\hline $\begin{array}{l}\text { Biochar, Carbon } \\
\text { sequestration, Soil } \\
\text { organic carbon, } \\
\text { Green house gas } \\
\text { and Climate change. }\end{array}$ & \\
\hline Article Info & \\
\hline $\begin{array}{l}\text { Accepted: } \\
\text { 06 March } 2017 \\
\text { Available Online: } \\
10 \text { April } 2017\end{array}$ & \\
\hline & \\
\hline
\end{tabular}

\section{Introduction}

Carbon is the most abundant element in living things and accounts for approximately $50 \%$ of the total mass of plants and animals. It is well known that the global carbon cycle is closely connected to global climate change largely through anthropogenic emissions of carbon dioxide originating from fossil fuel use and land use change (IPCC, 2007). Atmospheric concentration of $\mathrm{CO}_{2}$ has increased from $280 \mathrm{ppm}$ in pre industrial era to $\sim 385 \mathrm{ppm}$ in $2008(+37.5 \%)$ and is presently increasing at the rate of $\sim 2 \mathrm{ppm} \mathrm{yr}^{-1}$ or $3.5 \mathrm{Pg} \mathrm{yr}^{-1}(1 \mathrm{Pg}=$ 1 billion metric ton) (IPCC, 2007). There exist a strong link between food insecurity and 
climate change. The twin crisis of climate change and food insecurity can be addressed by restoring soil organic carbon pool through carbon sequestration in agro-ecosystems, especially in agricultural soils. The global potential of $\mathrm{C}$ sequestration in soils of agroecosystems is about 2.1 billion tons $\mathrm{C}$ year ${ }^{-1}$ (Lal, 2010). Increase in soil $C$ pool leads to reduction in atmospheric concentration of $\mathrm{CO}_{2}$ because a part of the photosynthesized biomass is converted into stable humus with a long mean residence time in soil. There are a number of options for carbon sequestration in agro-ecosystems (Lal, 2010) but the modern approach is the soil application of biochar, charcoal created by low-temperature pyrolysis of biomass under anaerobic conditions (Zimmeman, 2010). Biochar is produced by pyrolysis and is dominantly composed of aromatic compounds that are largely resistant to biological degradation (Baldock and Smernik, 2002). Biochar is a highly carbonized material in which the carbon content varies depending on the feedstock and production conditions. It was reported that the total $\mathrm{C}$ content was highest in maize biochar (66\%) followed by pearl millet biochar (64\%), wheat biochar (64\%) and rice biochar (60\%) (Purakayastha et al., 2015). Due to its relative inertness, biochar application contributes to the soil refractory organic C pool (Glaser et al., 2001; Marris, 2006). Biochar is receiving much attention as a potential tool for mitigating climate change through long-term biological carbon sequestration. The potential of biochar application for soil organic carbon sequestration may be 1 billion tons $\mathrm{C}$ year ${ }^{-1}$ (Sohi et al., 2010) or more (Lehmann et al., 2006).

\section{What is biochar?}

Biochar is the product of thermal degradation of organic materials in the absence of oxygen (pyrolysis), and is distinguished from charcoal by its use as a soil amendment.
Biochar is a fine grained, highly carbonaceous, pyrolysed (low temperature) product of biomass. The pyrolysis temperature strongly influences the stability of biochar in soil; the higher the pyrolysis temperature higher would be the stability (Purakayastha et al., 2015). Biochar is charred organic product which made up of biologically recalcitrant carbon that is not easily mineralized by the soil microbes (Chan and $\mathrm{Xu}, 2009)$. The carbon present in the biochar is in aromatic form which offer a higher degree of stability and resistant to decomposition, which making it a most important tool for carbon sequestration.

Biochar is a carbon rich charcoal-like substance created by thermal decomposition biomass (organic matter) in low oxygen conditions at relatively low temperatures $\left(<700^{\circ} \mathrm{C}\right)$, a process known as pyrolysis. Almost half of dry biomass weight is pure carbon. If biomass is left to decompose in air, almost all of the carbon is lost into the atmosphere within a few years. During pyrolysis, around $50 \%$ of biomass carbon is converted into biochar. Of the other $50 \%$, around two thirds can be released as useful energy. Thus $1 \mathrm{Mt}$ of dry biomass sequesters (locks away) 0.3 MT of carbon, equivalent to 1.2 MT $\mathrm{CO}_{2}$ (Bajiya et al., 2017). Thus, biochar could play an important role in helping to sequester carbon from the atmosphere. Its high stability in the environment relative to other types of organic $C$ substances is one of the important distinguishing properties of biochar. It has been estimated that biochar can persist up to 13,900 and 10,000 years sea and soils environments, respectively (Masiello and Druffel, 1998) However, long-term simulations show biochar-C can reside for 100 to 2000 years which may varies based on the location, soil, agro-climate and various agronomic management factors employed for crop production. Therefore, biochar addition to soil can provide a potential sink for $\mathrm{C}$ and 
known to reduce the $\mathrm{CO}_{2}$ release back to the atmosphere.

\section{Carbon sequestration}

Carbon sequestration is the process involved in carbon capture and the long-term storage of atmospheric carbon dioxide (Sedjo et al., 2012). Carbon sequestration involves longterm storage of carbon dioxide or other forms of carbon to mitigate or defer global warming. It has been proposed as a way to slow the atmospheric and marine accumulation of greenhouse gases, which are released by burning fossil fuels. Carbon dioxide $\left(\mathrm{CO}_{2}\right)$ is naturally captured from the atmosphere through biological, chemical, and physical processes. Artificial processes have been devised to produce similar effects, including large-scale, artificial capture and sequestration of industrially produced $\mathrm{CO}_{2}$ using subsurface saline aquifers, reservoirs, ocean water, aging oil fields, or other carbon sinks. Soils are the largest terrestrial sink for carbon on the planet. World soils constitute the third largest global $\mathrm{C}$ pool, comprising of two distinct components: (i) soil organic $\mathrm{C}$ (SOC) estimated at $1550 \mathrm{Pg}$, and (ii) soil inorganic C (SIC) pool estimated at $950 \mathrm{Pg}$, both to one meter depth (Lal, 2004). The soil carbon sequestration is the long-term storage of carbon in soil which could well be accomplished by the application of biochar as a soil amendment (Purakayastha et al., 2015).

\section{Role of biochar in carbon sequestration}

Declining fertility status of cultivated lands due to declining level of SOC is a major anxiety especially in Asian and African countries left their soils with lower crop productivity and resource use efficiency. SOC being keystone to soil quality also reported to an important indicator of agricultural sustainability. Restoring SOC is important not only to achieve food security and soil quality but also to offset the negative impact of agricultural related climate change (Lal, 2004). Addition of biochar to soils has been recognized as one of the important strategy to counterbalance the impact of climate change through sequestering the carbondioxide $\left(\mathrm{CO}_{2}\right)$ into the soils so the load of excess atmospheric $\mathrm{CO}_{2}$ will reduced (Lehmann et al., 2006). To fulfill this purpose of carbon sequestration under wider agro-climatic situations we have to keep care of following two points. First, we have to convince the growers to cultivate the plants and suitable crops as they are being charred because the actual step of sequestering atmospheric $\mathrm{CO}_{2}$ with the help of biochar is solely depends on photosynthesis in plants. It is widely reported that the plant biomass synthesized in the plants through the process of photosynthesis on an annual basis can emit their carbon rapidly in the atmosphere due to faster decomposition. Decomposition of plant biomass contradictory to the biochar process and play a crucial role in the process of climate change as it release the bulk of carbon in the atmosphere that is fixed by the plants through photosynthesis. In contrast to decomposition, the process of transforming the photo synthetically fixed plant biomass into biochar that decomposes much more slowly (conversion of rapid biological cycle of $\mathrm{C}$ into a much slower biochar mediated $\mathrm{C}$ cycle) (Lehmann, 2007). Second, the finally charred material (biochar) should be more stable than the plant biomass from which it was formed. As the degree of stability of biochar is one of the important parameters that can widely use to evaluate its potential for carbon sequestration. The pyrolysis process through which the conversion of organic matter in biochar take place has significantly influences on the stability of the final product thus increases the recalcitrance of $\mathrm{C}$ in the biomass. The pyrolysis process may result into complete destruction of cellulose and lignin and the appearance of aromatic structures in the charred product that 
leading to significantly change in composition. These changes in the composition of organic materials through pyrolysis also have significant effect on the stability of biochar. To estimate the carbon sequestration potential and scaling out the quantity of atmospheric $\mathrm{CO}_{2}$ carbon sequestrated through biochar several approaches have been indentified and taken into consideration to provide first estimates of the large-scale potential of biochar sequestration and therefore its benefit in terms of higher crop productivity (Lehmann et al., 2006; Laird, 2008), but these approaches need to be perfected against economic and ecological constraints and extended to include a full emission balance of carbon. For example, the full balance of carbon emission require a comparison to a baseline scenario and at the same time showing what emissions of carbon have been reduced by changing of the product from plant material that utilizes biochar. Therefore, still more locations based depth studies that add in information density required to extrapolate to the global scale and at the same time simple comparison between global carbon fluxes emission in the atmosphere may need to suffice to demonstrate the potential of sequestration of carbon using biochar. It has been estimated that Earth's soils is stored around four times more organic $\mathrm{C}$ than in atmospheric $\mathrm{CO}_{2}$ (Lehmann, 2007). Likewise, the annual uptake of $\mathrm{CO}_{2}$ by plants for the process of photosynthesis is around eight times greater than today's anthropogenic $\mathrm{CO}_{2}$ emissions in the atmosphere. Therefore, there is clear cut evidence that a huge amount of $\mathrm{CO}_{2}$ are cycling between atmosphere and plants annually and soil is one of the most important source where most of the world's organic C is already stored in soil. So, if we are going to divert a very small proportion of this huge amount of cycling $\mathrm{C}$ into the soil with the help of biochar cycle would make a large difference to atmospheric $\mathrm{CO}_{2}$ concentrations but a very small difference to the global soil C storage. It has been already estimated that by diverting merely one per cent of annual net plant uptake into biochar would mitigate almost 10 per cent of current anthropogenic $\mathrm{C}$ emissions to the atmosphere in the form of carbon (Laird, 2008).

While evaluating for carbon sequestration potential stability of biochar is an important parameter since only a long half-life will ensure a relevant sequestration potential by offering a wider resistance towards decomposition of biochar through soil microbial communities. Stability of biochar simply determines how long carbon held in the soil in the form of biochar will remain sequestered in soil system and at the same time how long it may influence emissions of greenhouse gas from the soil system and help in the counterbalancing the effect of climate change. It has been found that conversion of plant biomass to biochar using pyrolysis process followed by its application to the soil increases the residence time of carbon $(C)$ in the soil as compare to when same plant biomass applied directly to the soil (Lehmann, 2007). The benefits of biochar in terms of higher carbon sequestration have been found significantly greater with increase in the stability of charred product.

\section{Influence of biochar on native soil organic carbon}

It has been widely reported fact that application of biochar contributes to the soil recalcitrant C pool (Glaser et al., 2001; Marris, 2006). Therefore, it's a promising alternative tool for sequester more $\mathrm{C}$ compared to traditional agricultural practices involving direct incorporation of plant biomass in the form of crop residues that results in rapid mineralization carbon leading to larger $\mathrm{CO}_{2}$ release in the atmosphere (Bruun et al., 2011). However, the results of 
many studies have been suggested both suppression and stimulation of native SOC decomposition with the application of biochar (Liang et al., 2010; Cross and Sohi, 2011; Luo et al., 2011). The differences in the nature of material used for biochar formation and soil, and incubation conditions and agronomic factors of different studies leads to inconsistent results (Jones et al., 2011). The higher rates of mineralization than predicted indicate positive priming of a specific $\mathrm{C}$ source, whereas lower than that predicted indicate negative priming. In general, at low temperature $\left(250\right.$ and $\left.400^{\circ} \mathrm{C}\right)$ biochar-C mineralization was positively primed during early incubation stage (Zimmerman et al., 2011).

Biochar is a stable product when applied to soil, it remains in soil for centuries and securely store $\mathrm{C}$ for long-term $\mathrm{C}$ sequestration due to more resistance towards decomposition by soil microbes. It has been estimated that in India about 309 million tons of biochar (eqv. to 154 MT of biochar C) could be produced annually by using the plant residues, the application of which might offset about

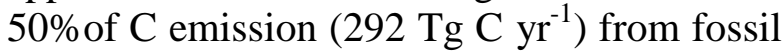
fuel (Lal, 2004). Additionally both heat and gases can be captured during production of biochar by pyrolysis to produce energy carriers such as electricity, bio-oil, or hydrogen and certain other valuable coproducts.

\section{Carbon sequestration and greenhouse gas emission}

Long term application of biochar to soil may result in net removal of carbon from the atmosphere particularly over time. With the use of biochar the mitigation of carbon emissions is obtained not only through its application and long term storage in the soil, but also from substitution of fossil fuel by the produced bio-oil that also one of the major source of green house gas emission in the atmosphere (Cross and Sohi, 2011). The stability of charred biochar is one of the basic and important criteria that will decide its half life in the soil system. The one approach which may employ to increases the stability of biochar is by raising the pyrolysis temperature, but this will be at the expense of the quantity produced (Luo et al., 2011). Interestingly, the highest biochar carbon sequestration is achieved at $500{ }^{\circ} \mathrm{C}$, despite the fact that biochar made at higher temperatures is relatively more recalcitrant than low temperature biochars. As biochar is highly resistant to microbial decomposition and application of biochar to the agricultural soils has a significant potential to mitigate greenhouse gases emissions. For example, Liang et al., 2014 reported that $\mathrm{CH}_{4}$ emissions from the paddy field were significantly decreased with the application of corn stalk biochar.

PCR study of the same experiment further revealed that biochar amendments (1) increased methanotrophic bacterial abundances significantly, and (2) decreased the ratios of methanogenic to methanotrophic abundances greatly that untimely resulted into lower dawn the emission of methane with biochar application.

Likewise, application of biochar to soil inconjugation with mineral fertilisers can reduce $\mathrm{N}_{2} \mathrm{O}$ emissions without suppressing the mineralisation or nitrification processes. For example, application of biochar decreased not only the cumulative $\mathrm{N}_{2} \mathrm{O}(52-84 \%)$ but also the NO (47-67\%) emissions compared to control or mineral fertilizer application (Nelissen et al., 2014). Further it has been reported that $\mathrm{N}_{2} \mathrm{O}$ emissions were more decreased at high compared to low pyrolysis temperature. According to a recent estimation the maximum carbon sequestration potential of biochar in the world is $2.27 \mathrm{Pg} \mathrm{C}_{\text {year }}{ }^{-1}$. 


\section{Potential and role of biochar in enhancing carbon sequestration}

According to an estimate approximately 500550 MT of crop residues are produced per year in India. It consist of 93.9 MT of wheat, 104.6 MT of rice, 21.6 MT of maize, 20.7 MT of millets, 357.7 MT of sugarcane, 8.1 MT of fiber crops, 17.2 MT of pulses and 30.0 MT of oilseeds crops, in the year 2011-12 (MOA, 2012). Disposal of this crop residue remains a key issue in rural farm areas and city organic waste in urban societies. Most wastes are either burnt or end up in landfill, which degrade the environment and also produce large amounts of GHGs. The production of biochar from farm wastes and their application in farm soils offer multiple environmental and financial benefits. Biochar use has a very promising potential for global climate change mitigation. There is significant availability of non-feed biomass resources in the country as potential feedstock for biochar production. Biochar having high $\mathrm{pH}$ value can be a good remedy for acid soil amelioration. If only $1 \%$ of this biomass is converted to biochar, about 74 thousand tons of carbon can be sequestered annually. The sequestration potential depends on climate, soil type and site specific management. Soil organic carbon of crop land increases only if either soil organic carbon additions are enhanced or decomposition rates reduced. Reduced decomposition is an advantage of charcoal (biochar). As the soil organic carbon pool declines due to cultivation, the more resistant charcoal fraction increases as a portion of the total carbon pool and may constitute up to $35 \%$ of the total soil organic carbon pool in ecosystems (Skjemstad et al., 2002). Only $2-20 \%$ of the carbon added as above ground residues and root biomass enters the soil organic carbon pool by humification. The rest is converted to $\mathrm{CO}_{2}$ due to oxidation (Lal, 2004).
About $50 \%$ of the carbon can be captured if biomass is converted to biochar (Lehmann et al., 2006). Globally, soil is estimated to hold more organic carbon $(1,100$ GT; 1 $\mathrm{GT}=1,000,000,000$ tonnes) than the atmosphere (750 GT) and the terrestrial biosphere (560 GT) (Post et al., 1990). The global flux of $\mathrm{CO}_{2}$ from soils to the atmosphere is in the region of $60 \mathrm{GT}$ of carbon per year due to microbial respiration and decomposition of soil organic matter $(\mathrm{SOM})$. Biochar are considerably more recalcitrant than soil organic matter and decomposes very slowly, over a time frame. Thus, biochar allows more carbon input as compared to the carbon output and this is the basis behind biochar's possible carbon negativity and hence it's potential for climate change mitigation. It is highly stable against microbial decomposition and hence reduces GHG emissions. Agricultural waste containing high silica are not suitable for biochar, because silica entrapping carbon during combustion (Raveendran et al., 1995). Further, studies showed that the highest biochar carbon sequestration is achieved at $500^{\circ} \mathrm{C}$, despite the fact that biochar made at higher temperatures is relatively more recalcitrant than low temperature biochars. However, $\mathrm{CO}_{2}$ is also emitted during the process of pyrolysis, transportation and application. Therefore, estimating the net carbon sequestration potential should consider these CO2 emissions. Kameyama et al., 2010 estimated the net carbon sequestration potential of farmland application of bagasse charcoal produced by the pilot plant and it was estimated that 0.3 and 0.2 ton $\mathrm{CO}_{2} \mathrm{t}^{-1}$ dry weight for dry feedstock (MC 20\%) and wet feedstock (MC 50\%), respectively. These values corresponded to $70 \%$ and $50 \%$ of the carbon stabilized as bagasse charcoal in Japan. Lehmann et al., 2006 predicted that the biochar storage capacity of global crop land and temperate grassland is $\sim 400 \mathrm{GT} \mathrm{C}$, which 
would be equivalent to a $\sim 25 \%$ increase in global soil carbon. Lenton and Vaughan, 2009 calculated a reduction in atmospheric carbon of up to 22 GT C (equivalent to a reduction of 10 ppm $\mathrm{CO}_{2}$ ) by 2050. Continuing the trend forward, they predicted 3.15 GT C $\mathrm{yr}^{-1}$ could be sequestered by 2100 . Thus conversion of crop residue to biochar and its utilization in agricultural land has showed a very high potential in sequestering $\mathrm{C}$ in soil and mitigating the adverse effect of climate change.

In conclusion, biochar is a novel approach for establishing a sink for soil carbon sequestration and reported to increase the SOC over time. The interaction mechanisms with different soil constituents and fate in different soil types, agro-ecologies and agronomic and soil management practices especially under long-term condition, its yield and stability should be studied to have a better understanding of biochar in soil systems. So, wide-scale dissemination of biochar technology for carbon sequestration and climate change mitigation needs intensive investigation. To derive the maximum possible benefit of carbon sequestration through application of biochar, both yield and stability of the biochar are two important factors and should be optimized. The benefits of carbon sequestration through biochar are more visible in soils lower in carbon than soils relatively higher in carbon. The knowledge on mechanism of biochar induced reduction in greenhouse gas emission can be applied to develop a more effective greenhouse gas mitigation process for paddy fields.

\section{References}

Bruun, E.W., Müller Stöver, D., Ambus, P. and Hauggaard Nielsen, H. 2011. Application of biochar to soil and $\mathrm{N} 2 \mathrm{O}$ emissions: potential effects of blending fast pyrolysis biochar with anaerobically digested slurry. European J. Soil Sci., 62(4): 581589.

Chan, K.Y. and Xu, Z. 2009. Biochar: nutrient properties and their enhancement. Sci. Technol., 1(1): 67-84.

Cross, A. and Sohi, S.P. 2011. The priming potential of biochar products in relation to labile carbon contents and soil organic matter status. Soil Biol. Biochem., 43(10): 2127-2134.

Glaser, B., Haumaier, L., Guggenberger, G. and Zech, W. 2001. The Terra Preta'phenomenon: a model for sustainable agriculture in the humid tropics. Naturwissenschaften, 88(1): 3741.

IPCC. 2007. "Climate Change 2007: The Physical Science Basis. Summary for Policymakers", Contribution of Working Group I to the Fourth Assessment Report of the Intergovernmental Panel on Climate Change.

Jones, D.L., Murphy, D.V., Khalid, M., Ahmad, W., Edwards-Jones, G. and DeLuca, T.H. 2011. Short-term biochar-induced increase in soil $\mathrm{CO} 2$ release is both biotically and abiotically mediated. Soil Biol. Biochem., 43(8): 1723-1731.

Kameyama, K., Miyamoto, T., Shiono, T. and Shinogi, Y. 2012. Influence of sugarcane bagasse-derived biochar application on nitrate leaching in calcaric dark red soil. J. Environ. Quality, 41(4): 1131-1137.

Laird, D.A. 2008. The charcoal vision: a winwin-win scenario for simultaneously producing bioenergy, permanently sequestering carbon, while improving soil and water quality. Agronomy J., 100(1): 178-181.

Laird, D.A., Fleming, P., Davis, D.D., Horton, R., Wang, B. and Karlen, D.L. 2010. Impact of biochar amendments on the quality of a typical Midwestern agricultural soil. Geoderma, 158(3): 443449.

Lal, R. 2004. Soil carbon sequestration impacts on global climate change and food security. Sci., 304(5658): 1623-1627.

Lal, R. 2010. Managing soils and ecosystems 
for mitigating anthropogenic carbon emissions and advancing global food security. BioSci., 60(9): 708-721.

Lehmann, J. 2007. Bio energy in the black. Frontiers in Ecol. Environ., 5(7): 381387.

Lenton, T.M. and Vaughan, N.E. 2009. The radiative forcing potential of different climate geo engineering options. Atmospheric Chem. Physics, 9(15): 55395561.

Liang, F., Li, G.T., Lin, Q.M. and Zhao, X.R. 2014. Crop yield and soil properties in the first 3 years after biochar application to a calcareous soil. J. Integrative Agri., 13(3): 525-532.

Luo, Y., Durenkamp, M., De Nobili, M., Lin, Q. and Brookes, P.C. 2011. Short term soil priming effects and the mineralisation of biochar following its incorporation to soils of different pH. Soil Biol. Biochem., 43(11): 2304-2314.

Marris, E. 2006. Putting the carbon back: Black is the new green. Nature, 442(7103): 624626.

Masiello, C.A. and Druffel, E.R.M. 1998. Black carbon in deep-sea sediments. Sci., 280(5371): 1911-1913.

MoA. 2012. Ministry of Agriculture, Govt. of India, New Delhi. www.eands dacnet.nic.in.

Nelissen, V., Saha, B.K., Ruysschaert, G. and Boeckx, P. 2014. Effect of different biochar and fertilizer types on $\mathrm{N} 2 \mathrm{O}$ and NO emissions. Soil Biol. Biochem., 70: 244-255.

Post, W.M., Peng, T.H., Emanuel, W.R., King, A.W., Dale, V.H. and DeAngelis, D.L. 1990. The global carbon cycle. American Scientist, 78(4): 310-326.
Purakayastha, T.J., Kumari, S. and Pathak, H. 2015. Characterisation, stability, and microbial effects of four biochars produced from crop residues. Geoderma, 239: 293-303.

Raveendran, K., Ganesh, A. and Khilar, K.C. 1995. Influence of mineral matter on biomass pyrolysis characteristics. Fuel, 74(12): 1812-1822.

Rohitash Bajiya, Hansa Lakhran, Sandeep Kumar and Seema. 2017. Biochar for Enhancing Agricultural Sustainability under Climate Change. Int. J. Curr. Microbiol. Appl. Sci., 6(2): 1876- 1883.

Sedjo, R., and Sohngen, B. 2012. Carbon sequestration in forests and soils. Annu. Rev. Resour. Econ., 4(1): 127-144.

Skjemstad, J.O., Reicosky, D.C., Wilts, A.R. and McGowan, J.A. 2002. Charcoal carbon in US agricultural soils. Soil Sci. Society of America J., 66(4): 1249-1255.

Smernik, R.J., Baldock, J.A., Oades, J.M. and Whittaker, A.K. 2002. Determination of T $1 \rho \mathrm{H}$ relaxation rates in charred and uncharred wood and consequences for NMR quantitation. Solid State Nuclear Magnetic Resonance, 22(1): 50-70.

Sohi, S.P., Krull, E., Lopez-Capel, E. and Bol, R. 2010. A review of biochar and its use and function in soil. Adv. Agronomy, 105: 47-82.

Zimmerman, A.R. 2010. Abiotic and microbial oxidation of laboratory-produced black carbon (biochar. Environ. Sci. Technol., 44(4): 1295-1301.

Zimmerman, A.R., Gao, B. and Ahn, M.Y. 2011. Positive and negative carbon mineralization priming effects among a variety of biochar-amended soils. Soil Biol. Biochem., 43(6): 1169-1179.

\section{How to cite this article:}

Yadav, R.K., M.R. Yadav, Rakesh Kumar, C.M. Parihar, N. Yadav, R. Bajiya, H. Ram, R.K. Meena, D.K.Yadav and Yadav, B. 2017. Role of Biochar in Mitigation of Climate Change Through Carbon Sequestration. Int.J.Curr.Microbiol.App.Sci. 6(4): 859-866.

doi: https://doi.org/10.20546/ijcmas.2017.604.106 